\title{
A Summer Immersive Program for Global Engineering Education with Fo- cus on 3D Design and Structural Analyses
}

\author{
Prof. Soondo Kweon, Southern Illinois University, Edwardsville
}

Education Ph. D. in Mechanical Science and Engineering, University of Illinois at Urbana-Champaign (08/2004 - 04/2009), 3.96/4.0 Thesis advisor: Armand J. Beaudoin Thesis title: Edge cracking in rolling of an aluminum alloy AA2024 M. S. in Mechanical Design and Production Engineering, Feb 1995, Seoul National University, South Korea (03/1993 - 02/1995), 4.0/4.3 Thesis advisor: Sooik Oh Thesis title: A study on radiation effects in high temperature metal forming considering Shape Factor B. S. in Mechanical Design and Production Engineering with honors (cum laude, 9th/54, 3.6/4.3), Feb 1993, Seoul National University, South Korea (03/1989 - 02/1993) Professional positions Research experience Associate professor, Southern Illinois University at the department of mechanical engineering (07/2017 - current) Assistant professor, Southern Illinois University at the department of mechanical engineering (08/2011 - 06/2017) Postdoctoral researcher, Texas A\&M University at the department of aerospace engineering (04/2009 - 08/2011) Advisor: Amine Benzerga Research topics: Constitutive behaviors of polymer materials, computational dislocation dynamics, and mechanics of anisotropic ductile fracture Graduate research assistant, University of Illinois at Urbana-Champaign (10/2004-04/2009) - DOE Hot rolling scrap (Investigation of edge cracking of AA2024 using a crystal- plasticity-based damage model) Graduate research assistant, Seoul National University (03/1993-02/1995)

\section{Prof. Jun H. Park, Tongmyong University}

Jun-Hyub Park received the B.S. degree from Korea University, Seoul, Korea, in 1985, the M.S. and Ph.D. degrees in Mechanical Engineering from Korea Advanced Institute of Science and Technology, Taejeon, Korea, in 1987, 1995, respectively. He was a member of research staff of MEMS Laboratory in Samsung Advanced Institute of Technology. He works in School of Mechatronics Engineering, Tongmyong University as professor. His primary research interest is in reliability and fatigue life prediction of MEMS devices and mechanical structures.

\section{Prof. Kookhyun Kim, Tongmyong University}

Kookhyun Kim received the B.S. and M.S. degrees from Inha University, Incheon, Korea, in 1994 and 1996, respectively. He received the Ph.D. degrees from department of Naval Architecture \& Ocean Engineering in Pusan National University, Busan, S. Korea, in 2007. He worked as a principal researcher in Hanjin Heavy Industries \& Construction, Co., LTD. during 13 years. He has worked as an associate professor at School of Naval Architecture \& Ocean Engineering, Tongmyong University in Busan, Korea, since joining 2009. His primary research interest is noise and vibration control of large structures such as ships and offshore platforms.

\section{Dr. Kee Joo Kim, Tongmyong University}

Kee Joo Kim is a professor of Tongmyung University. He specialized in mechanical engineering in school years. He has experience to work in Ssangyong Motor Co. for about 16 years.

\section{Prof. Jeonghoon Song, Tongmyong University}

Jeonghoon Song received the B.S. degree from Hanyang University, Seoul, Korea, in 1992, the M.S. and Ph.D. degrees in Mechanical Engineering from Hanyang University Graduate School, Seoul, Korea, in 1995 and 2000, respectively. He works in School of Mechatronics Engineering, Tongmyong University as an associate professor. His primary research interest is in modeling and control of vehicle dynamics and mechanical systems.

\section{Dr. Hooi-Siang Kang, Universiti Teknologi Malaysia}


Dr. Hooi-Siang Kang is the Head of Marine Technology Laboratory in Faculty of Mechanical Engineering (FME) at Universiti Teknologi Malaysia (UTM). He enjoyed a successful career as a doctoral researcher in the well-known Offshore System Simulation Laboratory until 2015 under supervision of Professor M.H. Kim in the Department of Ocean Engineering at Texas A\&M University. He also served at SHELL Oil Company and 2H Offshore Inc. during his doctoral industrial training programs and involved in deep water oil and gas development projects.

As an Ocean Engineering specialist in Malaysia, he enjoyed a wide range of academia-industry relationship appointments in Malaysia. He serves at Malaysia oil and gas industry by actively involving as a cluster member in the deep-water cluster, which involved most of the Malaysia most important oil and gas industrial players, hosted by government relevant Malaysian Petroleum Research Cooperation (MPRC).

Dr. Kang also actively participated in European Union funded educational program Erasmus Plus for developing innovative teaching and learning strategies in open modeling and simulation environment for student-centered engineering education.

He is an associate member in United Kingdom based Royal Institution of Naval Architects (RINA), and a local sub-branch committee member of Malaysia Joint Branch of Royal Institution of Naval Architects and Institute of Marine Engineering, Science \& Technology (MJB RINA-IMarEST Southern Branch). He also joined International Association of Offshore Engineers (IAOE), which is based at Houston.

\section{Prof. H. Felix Lee, Southern Illinois University, Edwardsville}

H. Felix Lee is a professor in Industrial Engineering at Southern Illinois University, Edwardsville. He holds a Ph.D. in industrial and operations engineering from the University of Michigan. His area of interest is in 3D modeling and applications, CAD/CAM/CAE, manufacturing system design and planning, and computer simulation and OR. He renovated the industrial and manufacturing engineering curriculum with introduction of $\mathrm{CAD} / \mathrm{CAM} / \mathrm{CAE}$ and 3D modeling applications to manufacturing systems, and has taught Boeing engineers on the subjects for about 20 years. He was a recipient of NSF grants on developing a supply-chain manufacturing system and on developing an integrated design-aid tool for flexible manufacturing systems, and of AHA (American Heart Association) grant on volumetric assessment of epicardial adipose tissue using echocardiography . He authored a book on CAD on Unigraphics: Engineering Design in Computer Integrated Design and Manufacturing. His papers appear in numerous refereed journals, books, and proceedings. In 2004, he organized the CAD/CAM/CAE student design contest in the PLM (Product Lifecycle Management) World Conference and chaired the first five contests in 2004 through 2008. Lee is a member of SME, IIE, Tau Beta Pi, and Phi Kappa Phi. 


\title{
A Summer Immersive Program for Global Engineering Education with Focus on 3D Design and Structural Analyses
}

\author{
Soondo Kweon'1, Jun H. Park², Kookhyun Kim³ ${ }^{3}$ Keejoo Kim², Jeonghoon Song², Hooi- \\ Siang Kang ${ }^{4}$, and H. Felix Lee ${ }^{5}$ \\ ${ }^{1}$ Mechanical Engineering, Southern Illinois University, Edwardsville, IL 62026, USA \\ ${ }^{2}$ Mechatronics Engineering, Tongmyung University, Busan, S. Korea \\ ${ }^{3}$ Naval Architecture \& Ocean Engineering, Tongmyong University, Busan, S. Korea \\ ${ }^{4}$ Mechanical Engineering, Universiti Teknologi Malaysia, Johor Bahru, 81310 Johor, Malaysia \\ ${ }^{5}$ Industrial Engineering, Southern Illinois University, Edwardsville, IL 62026, USA and corresponding \\ author \\ E-mail addresses of authors: skweon@siue.edu, jhpark@tu.ac.kr, kimk@tu.ac.kr, \\ kjkim@tu.ac.kr, jhsong@tu.ac.kr, kanghs@utm.my, hflee@siue.edu
}

\begin{abstract}
As the world is becoming smaller and more and more connected in all levels, future engineers need to be trained to work in more global, adaptable, and teamwork environments where engineers from different cultures and disciplines work together and solve problems. In this paper, we present a summer immersive program that we ran to meet this need. Our program drew about 40 undergraduate students from universities from three different countries with various engineering disciplines including mechanical, industrial, civil, mechatronics, naval architecture and ocean engineering, and automotive engineering. These universities were Southern Illinois University Edwardsville (SIUE) in the United States, Tongmyong University (TU) in South Korea, and Universiti Teknologi Malaysia (UTM) in Malaysia. This program ran for two weeks in July 2017 (and August 2016) at TU in Busan, S. Korea. The program content was engineering design and analysis methods using 3D modeling that have applications to various disciplines. We used wellknown engineering design and structure analysis tools, CATIA and ABAQUS, respectively. In the first part of the program, students learned the methods and tools using lectures and individual/group projects, while in the second part students grouped into 11 teams and each team defined its own final project problem, divided work among its members, applied the first part knowledge to the problem and made a team presentation on its findings at the end of the two-week program. Teams were formed such that students experienced diversity and global nature with respect to their origins, disciplines, and genders. Students in the same teams mostly shared the same dorm rooms for teamwork and cultural exchanges. Students toured global industry plants and visited cultural sites. An invited expert on the naval architecture design and ocean engineering field presented real case studies to students. The post assessment shows that students were very pleased with the program and we plan to run the program again in summer 2018. In this paper, we will present our program content and schedule, sample team final projects, and program assessment outcome, and share experiences we gained from our global engineering education through this summer program.
\end{abstract}

Key words: Global Engineering Education, Summer Immersive Program, 3D Design and Structural Analysis 


\section{Background}

The collaboration between School of Engineering at SIUE (Southern Illinois University Edwardsville) and TU (Tongmyong University) dates back to 2011. The chancellor of TU visited SIUE in 2011 and the chancellor of SIUE visited TU in 2012, when they made an MOU (Memorandum of Understanding) about a 2+2 dual diploma program between the two schools. In 2015, the two schools offered a one-week summer camp (TU-SIUE Summer Project Camp) for senior engineering students where the participating students learned the design process using CAD design software CATIA and structural analysis software ANSYS. After receiving strong positive feedbacks from the students from both schools, the provost of TU suggested that the TU-SIUE Summer Project Camp be expanded to a 2-week summer course (3 credits, about 50 class hours for 10 days) that both SIUE and TU students can take. It was agreed that students should pay tuition to his/her school. This summer course was designed to be taken by engineering students from various engineering disciplines as one of their technical electives or senior design course after each unit's approval. The two schools also agreed that they would exchange senior design presentations; as part of this agreement, groups of TU engineering students visited SIUE in December, 2015, 2016 and 2017 to present their design works to SIUE engineering students and listen to design project presentations by SIUE students. In the 2-week summer program of 2017, students from Universiti Teknologi Malaysia (UTM) in Malaysia joined TU and SIUE students first time, and will join again in summer 2018.

Before offering our summer program, we looked at other existing summer study abroad programs on engineering education for benchmarking. The summer study abroad program by James Madison University offered in the University of Costa Rica, Costa Rica ${ }^{1}$ provided an example practice of cultural immersion where students from both schools were taught by a team of interuniversity faculty for exposure to Costa Rican culture, language, history and geography. Similar cultural-immersion study abroad programs were found in China ${ }^{2}$ where US students earned six credit hours toward their undergraduate degrees, and in Mexico ${ }^{3}$ where students and faculty from the University of Texas at El Paso and Carnegie Mellon University travelled to CETYS Universidad, Ensenada, Baja California, Mexico. A similar culturally immersive engineering study abroad summer program was found between UK and China ${ }^{4,5}$, in which students from University of Electronic Science and Technology in China travelled to the University of Glasgow in UK to study solid-state lighting in English over two weeks. These previous study abroad programs provided evidences that engineering education has become more and more global and offered the basis of the study abroad program in this paper. These previous programs were used as benchmarks for activities for cultural immersion, the length of the program, and the structure of the course, etc. 


\section{Course Content}

This 2-week summer course emphasizes design of products based on 3D modeling and Finite Element Analysis. High-level 3D solid modeling is taught using CATIA, which is one of the most widely used CAD software in the automobile and aerospace industries. To design more structurally safe, cost-effective, and easily manufacturable products, Finite Element Analysis using ABAQUS or ANSYS is taught along with brief lectures on the theory of Finite Element Method.

The objective of the course is as follows.

1. Understanding the basic steps to feature-based and solid modeling.

2. Constructing 3D models and assembly structures with CATIA

3. Generating 3D models for finite element analysis with CATIA.

4. Making complicated 3D models made up of multi-curvature surfaces and solids such as parts/body in automobiles and electronic appliances with CATIA

5. Understanding the basic theory of Finite Element Method.

6. Performing stress analysis using ABAQUS or ANSYS.

Lecture topics and contents are as follows.

\begin{tabular}{|c|c|c|}
\hline & 3D Modeling Part (CATIA) & Structural Analysis Part (ABAQUS) \\
\hline $\begin{array}{l}1^{\text {st }} \text { week } \\
\text { (5 days) } \\
2^{\text {nd }} \text { week } \\
\text { (2 days) }\end{array}$ & $\begin{array}{l}\text { 1. Fundamentals of } 3 \mathrm{D} \text { solid modeling } \\
\text { 2. Engineering drawings } \\
\text { 3. Basic and advanced part modeling } \\
\text { technique } \\
\text { 4. Basic and advanced assembly } \\
\text { modeling technique } \\
\text { 5. Solid models for finite element } \\
\text { analysis }\end{array}$ & $\begin{array}{l}\text { 1. Introduction to Finite Element } \\
\text { Method (FEM) } \\
\text { 2. The FEM process: mesh controls, } \\
\text { material property assignment (elastic } \\
\text { and elasto-plastic), loading and } \\
\text { boundary conditions, convergence and } \\
\text { solution techniques, and interpretation } \\
\text { of the results }\end{array}$ \\
\hline $\begin{array}{l}2^{\text {nd }} \text { week } \\
\text { (3 days) }\end{array}$ & \multicolumn{2}{|c|}{$\begin{array}{l}\text { Final project (team project) } \\
\text { Each team is made up of } 3 \text { or } 4 \text { students. } \\
\text { Each team chooses a product of their choice to make a 3D model and exports the } \\
\text { 3D model data to a data file. Then, the data file is imported into ABAQUS or } \\
\text { ANSYS to perform stress analyses. By applying the relevant boundary conditions } \\
\text { to the product usage, students learn how to improve the design of the product such } \\
\text { that the product becomes safer, more cost-effective and more easily } \\
\text { manufacturable. }\end{array}$} \\
\hline
\end{tabular}




\section{Educational and Cultural Tours}

Since the main content of the course are 3D modeling and structural analysis, relevant industries (Shipbuilding/Marine Engineering and Automobile Companies) that use the 3D modeling and structural analysis widely in their design and manufacturing processes are selected for the educational tour. The course provided a tour of Daewoo Shipbuilding and Marine Engineering Co., Ltd, which is located in the Geoje Island, South Korea in 2015, a tour of Hyundai Motors Ulsan Plant, Ulsan, South Korea, in 2016 and a tour of Renault Samsung Motors Plant in Busan, South Korea, in 2017. The students observed through the tours how the manufacturing and assembly processes of designed products are performed in the automobile and shipbuilding industries. The students obtained better understanding of the assembly and manufacturing processes, which in turn helps them to understand better the product design process since the design process must take into account the manufacturing and assembly processes in order for the products to be mass-produced.

In Busan, South Korea, is the United Nations Memorial Cemetery, which was built in 1951 to commemorate the United Nations soldiers from 16 different countries who were dispatched to Korea to fight in the Korean War (1950-1953) and died in the battle fields. The students visited the cemetery and museum, and had a time to learn about and pay respect to the soldiers who sacrificed their young lives in an East Asian country thousands of miles away from their home countries to protect the democracy and freedom of the world. We believe that this trip helped to educate the students on the Korean history influenced by many other countries around the world and to instill global value and citizenship in them.

\section{Lectures, Labs and Final Project}

The course was designed to finish over 2 weeks. Therefore, the schedule of the class and practice lab sessions was tight. A typical week day schedule was as follows.

9:00 AM - 10:25 AM: CATIA lecture

10:35 AM - 12:00 PM: CATIA practice lab session

1:00 PM - 2:00 PM: ABAQUS lecture

2:00 PM - 3:00 PM: ABAQUS practice lab session

As shown in the schedule, the lecture and lab sessions were done in series everyday so that the students could practice what they learned each day. The instructors (two faculty members from SIUE taught the CATIA 3D modeling for product design and the ABAQUS/ANSYS structural analyses according their respective expertise) helped the students in the practice lab sessions. In the first week and the first two days of the second week, the students learned the theory and the tools (CATIA and ABAQUS/ANSYS) through lectures and individual/group projects. While they were learning the basic theory and the tools in the first week, students were grouped to 
teams for the final projects so that they could start thinking about their final projects. Each team was made up of 3 or 4 members. Teams were formed such that the students maximally experienced diversity and global nature with respect to their country origins, disciplines and genders. For example, in 2017, about 24 TU students from South Korea, 12 SIUE students from USA and 4 Universiti Teknologi Malaysia (UTM) students from Malaysia took this course. About $20 \%$ of the students were female. Their majors were ME (Mechanical Engineering), IE (Industrial Engineering), CE (Civil Engineering), Port Logistics Engineering, Mechatronics Engineering, Naval Architecture and Ocean Engineering, Electronic Engineering, Refrigeration \& Air-Conditioning Engineering and Automotive Engineering. In summer 2017, 11 teams were formed and each team defined its own final project problem before the beginning of the second week, divided work among its members, applied the knowledge that they learned in the first week to the problem and made a team presentation on its findings at the end of the second week.

We also had an invited expert, who is a faculty member from Universiti Teknologi Malaysia (UTM), presented to the students real case studies on design and analyses in the area of naval architecture and ocean engineering.

The final projects that the students worked on in summer 2017 include a bike pedal system, a subsystem of a combustion engine assembly, a bridge, a drone support bracket system, a scissor jack, a butterfly valve assembly, and a carabiner, etc. Although this summer course is just 2 weeks long, the students were able to develop their 3D CAD design and FEM analysis skills quickly and complete projects of decent difficulty and complexity successfully. We attribute to this success the following 3 factors: (a) daily intensive lectures reinforced by hands-on projectlab sessions, (b) team chemistry fostered from day 1 through activities described in the following paragraph, and (c) close interactions between the students and the two instructors. The instructors and students spent together almost 6 hours in class each day and lodged at the same dormitory that brew the intimate faculty-student mentoring atmosphere which subsequently helped to accelerate the student learning.

\section{Activities}

Students in the same team mostly shared the same dormitory room for teamwork and cultural exchanges. Since they belonged to the same team sharing the same dormitory room, they spent a lot of time together discussing about the projects and sharing their different cultures. The TU students often took the SIUE and UTM students to local restaurants and famous tourist places during the weekday evenings and over the weekends, which helped the students to understand better each other's cultures, and experience the local culture and form friendship. 


\section{Program Assessment}

Assessment of the student performance was done using lab assignments and tests that were given regularly in the first seven days. The students practiced what they learned, in order to do everyday homework and to perform well in the lab tests. The students spent the last three days on group work for their final project. The two instructors monitored the teams' progress on their projects and had constant discussion and feedback sessions. On the last day of the program, each team made a presentation on its final project followed by a Q/A session. The final presentation was evaluated by the two instructors from SIUE, a faculty member from Universiti Teknologi Malaysia (UTM) and the TU professors (the authors of this paper).

After the final presentation was done, an assessment form was handed out to the students to collect the program evaluation from the students. The questions used in the assessment form were as follows.

1. What were good things about this program for you?

2. What were negative things about this program for you that need improvements/changes for the future program offering?

3. Overall, was this program worth it for you? Would you recommend this course to others? Please give a brief explanation on your response to these questions.

The response results show that the students were highly satisfied with this immersive program and appreciated global, cultural, and multi-disciplinary learning experiences with hands-on design team projects. Example quotes are included as follows.

\section{Responses to Question 1:}

(I came to know many) new friends.

(I was able to) communicate with people of different backgrounds, races, religions and nationalities. I was exposed (to) communicate with students from USA and Korea.

I learned a lot from this program especially (on how to use) CATIA and ABAQUS. Besides, the spirit of teamwork and global spirit are built through this program. I really appreciate this opportunity given (to) me.

Being able to interact with people from different places and different cultural backgrounds, (...)

Very intensive and detail(ed) steps were taught.

Friendly and caring new friends (were) made from all (of) the three universities.

FEA can now be applied to all future CAD problems for design considerations. 
Making friends with my roommates and learning about the culture in South Korea. I was able to experience (the culture of) Korea.

On this program, I made many Korean friends and learned many useful skills. I was also exposed to an alien culture and environment, which eventually was not alien and I grew to love.

I enjoyed rooming with our teammates as it allowed all of us to form bonds faster.

I learned about Korean cultures by socializing with the Korean students.

I enjoyed learning of ABAQUS and CATIA. I had to communicate with them in English, which improved my English communication skills.

Response to Question 2:

Breakfast coupons should be given early.

Food.

I wish we had more materials available to us to further out ABAQUS knowledge even if it were only in written form.

I felt that the program was rushed.

(Hopefully it is) possible to make the class longer.

The program is too short.

A longer stay will improve the quality.

There were too many homework assignments, thus it was a little stressful.

Make the curfew time in the dormitory later than now.

The program was tough.

There was no time after school to make friends.

Make it less rigorous so that we can have more free time to get to know foreign students.

Response to Question 3:

(It is a) very worth 2-week program.

(I) would recommend this program to be conducted again in future.

(I) love this program.

I got to meet and understand new people and work with them. 
(I experienced) new cultures and (learned) different skills.

Yes. (It is a) very beneficial program.

(It is) totally worth for me. I surely recommend this course to others.

Learning ABAQUS and CATIA benefit all of us.

Yes, it was a good program.

It was a lot of fun and I learned a lot.

(I) would definitely recommend it to other students.

Absolutely, I would recommend this course.

This program is definitely worth it.

For 2 weeks, we took a course and experienced a foreign country.

Yes, this program was worth it because of the invaluable experience I had.

I would recommend this class to everyone at SIUE.

Yes. This program is greatly enjoyable.

I would highly recommend this course to others.

Learning about Korean cultures as well as ABAQUS and CATIA.

\section{Quantitative analysis of the assessment}

The assessment outcome in the previous section is analyzed quantitatively checking the number of positive and negative responses to Question 3, which is "Overall, was this program worth it for you? Would you recommend this course to others? Please give a brief explanation on your response to these questions." Table 1 has a summary of the statistical analysis. The survey indicates that 69.44 percent of the students expressed positive views while only $5.56 \%$ (just 2 students) showed negative opinions. The assessment was done anonymously. Therefore, it is assumed that the responses are genuine and shows objective assessment of the course. The faculty read the negative comments and will take them into account to improve the course next year. One possible explanation for those negative opinions is that we had a small number of students who majored in computer science and electrical engineering. These majors do not use FEM structural analyses, which caused those major students to lower their value for the program/course content. As a result of this assessment, we have decided not to admit these major students in the 2018 summer program, but limit it to other engineering majors that are relevant to 3D design and structure analyses. 
Table 1. Statistics on the responses to Question 3, "Overall, was this program worth it for you? Would you recommend this course to others? Please give a brief explanation on your response to these questions."

\begin{tabular}{|c|c|c|c|}
\hline $\begin{array}{c}\text { Number of positive } \\
\text { responses }\end{array}$ & $\begin{array}{c}\text { Number of neutral } \\
\text { responses }\end{array}$ & $\begin{array}{c}\text { Number of negative } \\
\text { responses }\end{array}$ & $\begin{array}{c}\text { Total number of } \\
\text { responses }\end{array}$ \\
\hline 25 & 9 & 2 & 36 \\
\hline $69.44 \%$ & $25 \%$ & $5.56 \%$ & $100 \%$ \\
\hline
\end{tabular}

Aside from the above assessment, the SIUE students filled out a separate survey, which is the official course student evaluation. The relevant questions related with this specific study abroad courses are summarized in Table 2 below. Eight out of 12 SIUE students submitted their student evaluations. The result shows that the SIUE students overall are very satisfied with the activities (including the culture-immersion activities mentioned in the section "Educational and Cultural Tours") with average score 4.6 out of 5 . The result indicates as well that the majority of the SIUE students think that this study abroad course was interesting and motivated them to learn more with the average score 4.5 out of 5 .

Table 2. Student evaluation responses of the SIUE students.

\begin{tabular}{|l|c|c|c|c|c|c|c|}
\hline Questions & SA & A & NAN & D & SD & No & Mean \\
\hline $\begin{array}{l}\text { This course was interesting and } \\
\text { motivated you to learn more }\end{array}$ & 5 & 2 & 1 & 0 & 0 & 8 & 4.5 \\
\hline $\begin{array}{l}\text { The activities/assignments were } \\
\text { useful in helping me learn. }\end{array}$ & 5 & 3 & 0 & 0 & 0 & 8 & 4.625 \\
\hline
\end{tabular}

Responses: [SA] Strongly Agree=5 [A] Agree=4 [NAN] Neither Agree Nor Disagree=3 [D]

Disagree $=2[S D]$ Strongly Disagree $=1$

With the positive assessment results above, we have decided to make this program also available for international SIUE engineering students as we prepare for the 2018 summer program. In the previous years, we limited the eligibility to only domestic SIUE engineering students in order to give them an opportunity to immerse in another culture. We think that including engineering students from other countries like Turkey and India in the program along with students from US, Malaysia, and Korea will help to make the program more global while students still experience immersion in another culture.

\section{Conclusion}

It is evident that future engineers need to be trained to work in more global, adaptable, and teamwork environments where engineers from different cultures and disciplines work together and solve problems. In this paper we presented the 2-week immersive summer program we ran in 
2015 to 2017 at TU, Busan, South Korea in order to meet this need. The post assessment results show a clear evidence that students were very pleased with the program and the program helped to meet the need. Our last summer program attracted engineering students from 3 countries. In the future we intend to make the program more global by disseminating this program through engineering conferences and societies and recruiting engineering students from other countries. To support this cause, TU, the host institution, will subsidize the expenses for 2-week lodging and some meals for students attending the program.

\section{Acknowledgment}

The authors thank Tongmyong University for hosting and supporting this summer program. The authors also appreciate the two funding sources that supported this program, the CK (Creative Korea) funding and the PRIME (Program for Industrial Needs- Matched Education) funding from the South Korean government, which were awarded to Tongmyong University. The airfare and the cost for the dormitory and meals for the SIUE and UTM students were generously subsidized with the above two funds.

\section{References}

1. Altaii, K., Cavallini, H., 2008. Energy issues and study abroad experience in Costa Rica, ASEE Annual Conference and Exposition

2. Fry, C., Leman, G., 2009. The 15 program: The challenges of implementing a projectbased summer study abroad program that integrates technology and entrepreneurship in China, ASEE Annual Conference and Exposition

3. Hernandez, N.V., Taboada, H.A., Espiritu, J.F., Gomez, C., Azuz, I.A., 2016. Engineering together sustainable communities: Sustainability engineering in action, ASEE Annual Conference and Exposition

4. Meehan, K., Bremner, D. J., Phillips, K., 2016. Overseas immersion program: Solid-state lighting in two weeks, ASEE's 123rd Annual Conference \& Exposition, New Orleans, LA.

5. Meehan, K., Phillips, A., 2016. Inexpensive hands-on activities in solid state lighting, ASEE Annual Conference and Exposition 